\title{
Enhancement of Biological Pretreatment on Rice Straw by an Ionic Liquid or Surfactant
}

\author{
Ken-Lin Chang ${ }^{1,2}$, Chun-Hung Liu ${ }^{1}$, Paripok Phitsuwan ${ }^{3}{ }^{\mathbb{D}}$, Khanok Ratanakhanokchai ${ }^{3}{ }^{\mathbb{D}}$, Yung-Chang Lin ${ }^{4,5}$, \\ Cheng-Di Dong ${ }^{6}{ }^{\circledR}$, Ming-Hsun Lin ${ }^{6}$ and Gordon C. C. Yang ${ }^{1, *}$ \\ 1 Institute of Environmental Engineering, National Sun Yat-Sen University, Kaohsiung 804, Taiwan; \\ klchang@mail.nsysu.edu.tw (K.-L.C.); firebee168@gmail.com (C.-H.L.) \\ 2 Department of Public Health, College of Health Sciences, Kaohsiung Medical University, Kaohsiung 804, Taiwan \\ 3 Division of Biochemical Technology, School of Bioresources and Technology, King Mongkut's University of \\ Technology Thonburi, Bangkok 10150, Thailand; paripok.phi@kmutt.ac.th (P.P.); khanok.rat@kmutt.ac.th (K.R.) \\ 4 Center for Environmental Toxin and Emerging-Contaminant Research, Cheng Shiu University, \\ Kaohsiung 804, Taiwan; yclin@gcloud.csu.edu.tw \\ 5 Institute of Environmental Toxin and Emerging-Comtaminant, Cheng Shiu University, Kaohsiung 804, Taiwan \\ 6 Department of Marine Environmental Engineering, National Kaohsiung University of Science and Technology, \\ Kaohsiung 804, Taiwan; cddong@nkust.edu.tw (C.-D.D.); minghsun.lin.frank@gmail.com (M.-H.L.) \\ * Correspondence: gordon@mail.nsysu.edu.tw; Tel.: +886-7-5252000 (ext. 4407)
}

Citation: Chang, K.-L.; Liu, C.-H.; Phitsuwan, P.; Ratanakhanokchai, K.; Lin, Y.-C.; Dong, C.-D.; Lin, M.-H.; Yang, G.C.C. Enhancement of Biological Pretreatment on Rice Straw by an Ionic Liquid or Surfactant. Catalysts 2021, 11, 1274. https:// doi.org/10.3390/catal11111274

Academic Editor: Claudia Carlucci

Received: 8 August 2021

Accepted: 20 October 2021

Published: 22 October 2021

Publisher's Note: MDPI stays neutral with regard to jurisdictional claims in published maps and institutional affiliations.

Copyright: (c) 2021 by the authors. Licensee MDPI, Basel, Switzerland. This article is an open access article distributed under the terms and conditions of the Creative Commons Attribution (CC BY) license (https:/ / creativecommons.org/licenses/by/ $4.0 /)$.

\begin{abstract}
Fungal delignification can be a feasible process to pretreat biomass for bioethanol production if its performance is improved in terms of efficiency through a few modifications. The aim of this study was to enhance the biodelignification pretreatment of rice straw using laccase in the presence of ionic liquid (1-Allyl-3-methylimidazolium chloride, [AMIM]Cl) or surfactant (TritonX-100). Addition of $750 \mathrm{mg} / \mathrm{L}$ [AMIM]Cl and $500 \mathrm{mg} / \mathrm{L}$ TritonX-100 increases the lignin removal to $18.49 \%$ and $31.79 \%$, which is higher than that of laccase only $(11.97 \%)$. The enzymatic saccharification process was carried out based on different strategies. The highest cellulose conversion, $40.96 \%, 38.24 \%$, and $37.91 \%$, was obtained after $72 \mathrm{~h}$ of enzymatic saccharification when the substrate was washed with distilled water after pretreatment of rice straw with laccase + TritonX-100, laccase + [AMIM]Cl, and laccase only, respectively. In addition, the morphology and structure changes of pretreated and untreated rice straw were studied. Both surface area and cellulose crystallinity are substantially altered after laccase $+[\mathrm{AMIM}] \mathrm{Cl}$ and laccase + TritonX-100 pretreatment. Enhanced saccharification efficiency of rice straw was achieved by laccase pretreatment with ionic liquid or surfactant in a single system.
\end{abstract}

Keywords: laccase; ionic liquid; surfactant; pretreatment; biomass; delignification

\section{Introduction}

The rapidly growing demand for energy, uncertainty about costs, and concerns about environmental impact have led to an interest in alternative energy resources such as bioethanol. Lignocellulosic biomass is considered as a potential alternative for conventional energy resources such as fossil fuels. Modern biomass will probably increase its share of the bioenergy supply [1]. The conversion of lignocellulosic biomass to bioethanol is a practical option for the improvement of energy security and reduction of greenhouse gas emissions [2,3]. Rice straw is one of the abundant lignocellulosic waste materials worldwide. Rice straw is produced annually in large quantities (731 million tons), which is distributed among Africa (20.9 million tons), Asia (667.6 million tons), America (37.2 million tons), and Europe (3.9 million tons). This amount of rice straw potentially produces 730 billion liters of bioethanol per year [4]. The largest part of the produced rice straw is disposed by incorporation into the soil or open burning in a field. Its accumulation in the soil deteriorates the ecosystem via waste disposal; burning contributes to emissions of harmful air pollutants, which can severely impact human health [5]. 
Rice straw contains cellulose, hemicellulose, and lignin, which naturally block its deconstruction by microbes. Therefore, pretreatment is required to enhance the accessibility of rice straw for the conversion of cellulose into fermentable sugars. Consequently, several physical (irradiation, mechanical pretreatment, and microwaves), chemical (organosolv, acid, and alkaline pretreatment), physicochemical (steam explosion, ammonia fiber explosion, and liquid hot water), and biological pretreatment methods have been reported [6-8]. Among the various pretreatment technologies, the biological methods have been extensively studied because they are inexpensive and have low energy and mild environmental condition requirements compared with other pretreatment methods [9].

Fungal species are capable of producing enzymes, which play a key role in biological pretreatment. They can biodegrade lignin and increase the accessibility of the biomass structure [10]. Many ligninolytic enzymes, such as laccase, manganese peroxidase, and lignin peroxidase, have been extensively used to degrade the lignin of lignocellulosic biomass [11,12]. Among them, laccase is the most easily accessible enzyme to lignin. Laccase is a multicopper oxidase that oxidizes substituted phenols using molecular oxygen as the final electron acceptor. The direct action of laccase on lignin is in principle restricted to phenolic units that only represent a small percentage of the total polymer, a fact that limits its biotechnological application. Due to the low efficiency of bio-based delignification methods, this pretreatment process needs to be improved.

Recently, studies indicated that the combination of thermal, chemical, or physical pretreatment processes with biological pretreatment increases the lignin removal and enzymatic digestibility: for example, milling and biological pretreatment with Pleurotus ostreatus [13], steam explosion and biological pretreatment with Sclerotium sp. laccase [14], and sodium hydroxide and biological pretreatment with Irpex lacteus [15]. However, the two-step pretreatment process is more cost-intensive and has higher energy requirements when compared with a single system. Therefore, the improvement of biological pretreatment in a single system has been of interest. The application of ionic liquids (ILs) and surfactants has been recommended to improve the pretreatment methods [16-18]; however, the combination of ILs and surfactants with a biodelignification process has not been reported in a single system.

The objective of this study was therefore to enhance the delignification and saccharification yields of rice straw using laccase (T. versicolor) in the presence of [AMIM]Cl or TritonX-100. The concentrations of [AMIM] Cl and TritonX-100 for high lignin removal were also investigated. The effect of the pretreatment was evaluated by performing enzymatic saccharification using different strategies. The changes in morphology, structure, and composition of the pretreated and untreated rice straw were studied by Fourier transform infrared spectroscopy (FTIR), scanning electron microscopy (SEM), atomic force microscopy (AFM), and X-ray diffraction (XRD).

\section{Results and Discussion}

\subsection{Effect of Laccase and Laccase with IL or Surfactant Pretreatment on Rice Straw Delignification}

To improve the lignin removal via laccase, different kinds of ILs ([AMIM]Cl and [BMIM]Cl) and surfactants (Rhamnolipid, Triton X-100, SDS, Tween 80, and CTAB) were tested as additions. Among them, [AMIM] $\mathrm{Cl}$ and TritonX-100 show the optimum efficiency. The effect of [AMIM]Cl and TritonX-100 concentrations on the lignin removal during laccase pretreatment is shown in Figure 1a,b. The lignin content gradually decreases with increasing [AMIM] $\mathrm{Cl}$ and TritonX-100 concentrations. The highest lignin removal, $31.79 \%$ and $18.49 \%$, was observed when $500 \mathrm{mg} / \mathrm{L}$ TritonX-100 and $750 \mathrm{mg} / \mathrm{L}$ [AMIM]Cl, respectively, were added. No notable lignin removal was observed with further increase of both surfactant and IL. IL is known to be capable of lignin removal, which might have practical advantages for the enzymatic saccharification of cellulose. Thus, the following concentrations of [AMIM] $\mathrm{Cl}$ and TritonX-100, respectively, were selected for subsequent experiments: $750 \mathrm{mg} / \mathrm{L}$ and $500 \mathrm{mg} / \mathrm{L}$. 

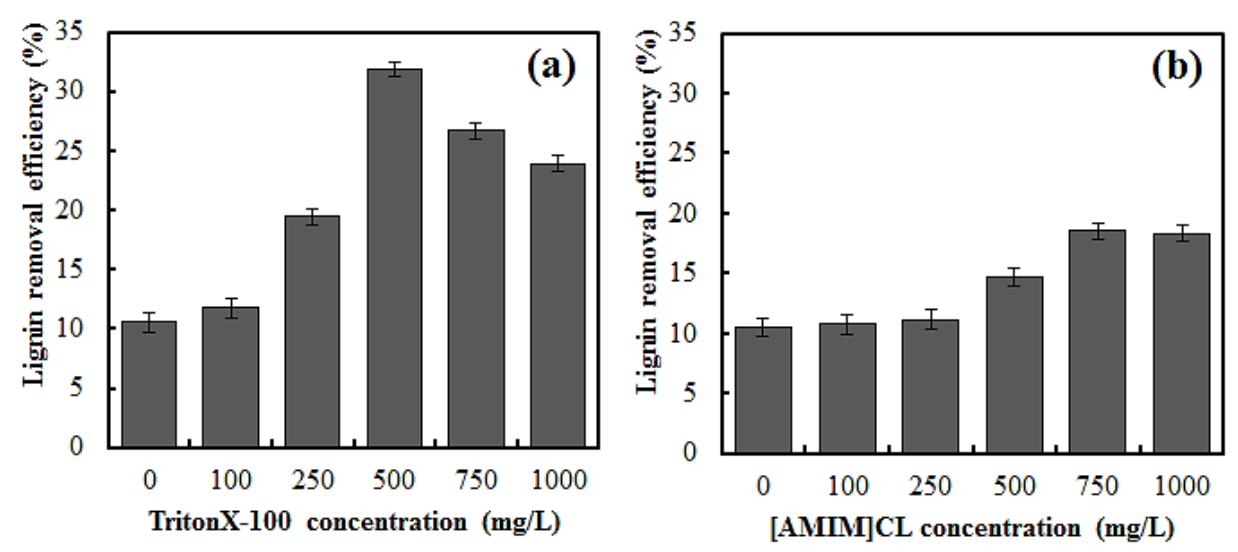

Figure 1. Effect of IL and surfactant concentrations on biological lignin removal efficiency. (a) $[\mathrm{AMIM}] \mathrm{Cl}$ concentrations and (b) TritonX-100 concentrations.

\subsection{Effect of Laccase and Laccase with IL or Surfactant Pretreatment on the Rice Straw Composition}

The chemical compositions of rice straw before and after laccase-only, laccase with IL, or surfactant pretreatment are summarized in Table 1. The untreated rice straw consists of $31.73 \%$ cellulose, $23.21 \%$ hemicellulose, $15.79 \%$ lignin, $21.46 \%$ ash, and $4.62 \%$ water. The pretreatment of rice straw with laccase only, laccase $+[\mathrm{AMIM}] \mathrm{Cl}$, or laccase + TritonX-100 led to an effective lignin removal of $11.96 \%, 18.49 \%$, and $31.75 \%$, respectively. Adding $500 \mathrm{mg} / \mathrm{L}$ TritonX-100 generated the highest lignin removal, increased by $22.52 \%$, compared with the laccase pretreatment only. These results indicate that the addition of IL and surfactant could enhance the lignin removal due to the reasons mentioned above. Additionally, this process also removes the hemicellulose content, which is $21.67 \%, 21.24 \%$, and $19.66 \%$ after pretreating rice straw with laccase only, laccase $+[\mathrm{AMIM}] \mathrm{Cl}$, and laccase + TritonX-100, respectively, compared with untreated. However, hemicellulose removal increases the surface area and reduces unproductive enzyme binding and therefore increases the probability of cellulose to be hydrolyzed [19]. The cellulose contents are $38.50 \%$, $39.57 \%$, and $40.83 \%$ after pretreating the rice straw with laccase only, laccase + [AMIM]Cl, and laccase + TritonX-100; it increased due to the partial removal of lignin and hemicellulose. The surfactant has a hydrophilic and a hydrophobic side and can bind to both lignin (hydrophobic side) and water (hydrophilic side), pulling the lignin into the water and enhancing its solubility; hence, the addition of surfactant to the delignification environment improves the lignin removal efficiency. In line with our results, several studies have indicated that IL is effective in removing lignin $[20,21]$. Moreover, ILs have been found to be capable of supporting and improving activity and stability of enzymes including laccases [22].

Table 1. Chemical composition of untreated and pretreated rice straw in dry weight.

\begin{tabular}{ccccc}
\hline Pretreatment & Lignin (\%) & Cellulose (\%) & $\begin{array}{c}\text { Hemicellulose } \\
\mathbf{( \% )}\end{array}$ & $\begin{array}{c}\text { Recovered } \\
\text { Solids (\%) }\end{array}$ \\
\hline Untreated & $15.79 \pm 0.01$ & $31.73 \pm 0.02$ & $23.21 \pm 0.03$ & 100.00 \\
L & $13.90 \pm 0.01$ & $38.50 \pm 0.02$ & $21.67 \pm 0.03$ & 94.25 \\
L + [AMIM]Cl & $12.87 \pm 0.01$ & $39.57 \pm 0.02$ & $21.34 \pm 0.04$ & 93.91 \\
L + TritonX-100 & $10.77 \pm 0.01$ & $40.83 \pm 0.02$ & $19.66 \pm 0.04$ & 93.23 \\
\hline
\end{tabular}

2.3. Effect of Laccase and Laccase with IL or Surfactant Pretreatment on Enzymatic Saccharification Based on Different Strategies

The percentages of cellulose conversion from untreated and pretreated rice straw with laccase only, laccase $+[\mathrm{AMIM}] \mathrm{Cl}$, and laccase + TritonX-100 using four enzymatic saccharification strategies are shown in Figure 2. Laccase pretreatment significantly increases the cellulose conversion compared with untreated rice straw. The highest cellulose conversion, $40.96 \%, 38.24 \%$, and $37.91 \%$, was obtained after $72 \mathrm{~h}$ of enzymatic hydrolysis when the substrate was washed with distilled water after laccase + TritonX-100, laccase + [AMIM]Cl, 
and laccase-only pretreatment, respectively (Figure 2a). The greater amount of lignin removal by laccase and laccase with IL or surfactant pretreatment (Table 1) could account for this improvement in enzymatic saccharification. After $72 \mathrm{~h}$ of enzymatic saccharification, the cellulose conversion via the simultaneous pretreatment and enzymatic saccharification increased from $15.92 \%$ (untreated rice straw) to 35.90\% (laccase + [AMIM]Cl), which is larger than that of laccase + TritonX-100 and the laccase-only pretreatment using the same enzymatic hydrolysis strategy (Figure $2 \mathrm{~d}$ ). Almost the same cellulose conversion was observed for the substrate that was not filtrated and washed before enzymatic hydrolysis (Figure 2c). The cellulose conversion increased to $25.58 \%$ (laccase + TritonX-100), 24.95\% (laccase + [AMIM]Cl), and $24.51 \%$ (laccase only) when the laccase was deactivated at $100{ }^{\circ} \mathrm{C}$ for $20 \mathrm{~min}$ (Figure $2 \mathrm{~b}$ ). The maximum cellulose conversion was obtained from the washed process because some of the inhibitions associated with pretreatment could be removed by washing. Moirangthem et al. pretreated rice straw by pressurized microwave and digestion with enzymes. However, the rice straw required a pretreatment above $160{ }^{\circ} \mathrm{C}$ for $5 \mathrm{~min}$ to obtain a significant impact on the subsequent enzyme hydrolysis [23]. Compared with our study, biological pretreatment could occur under mild conditions but with a longer reaction time.
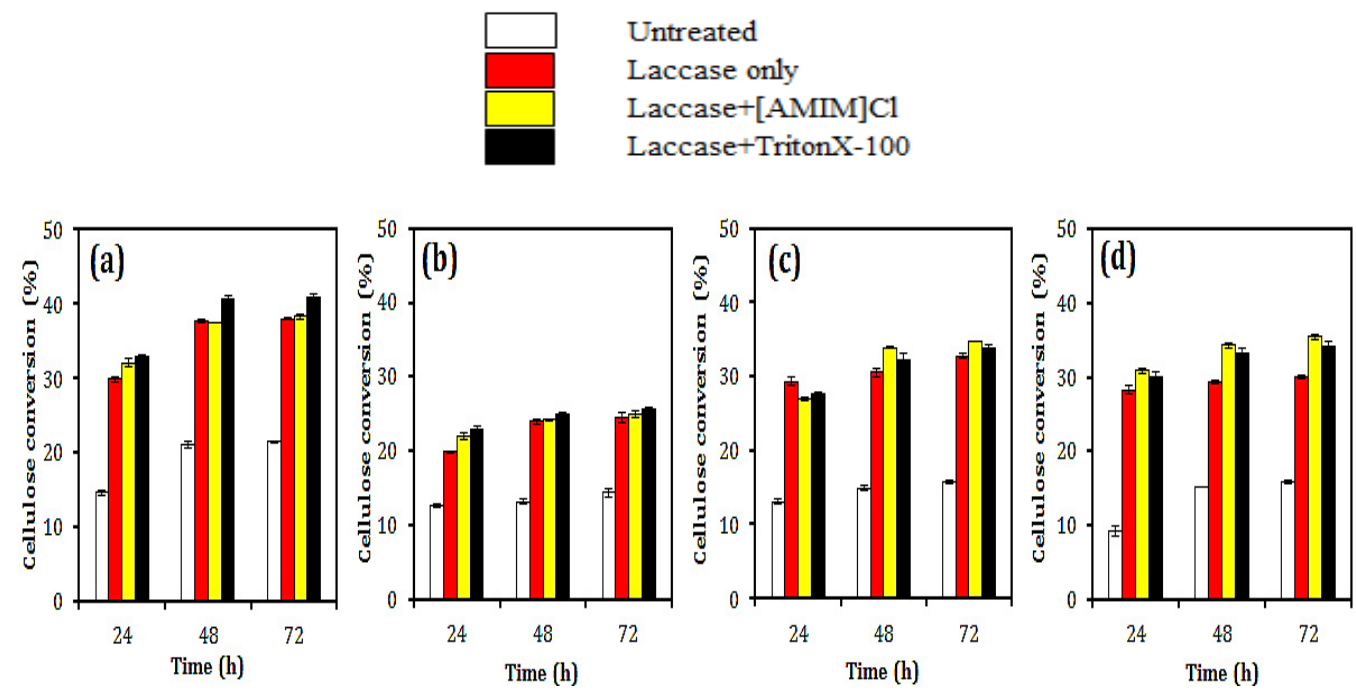

Figure 2. Profiles of enzymatic hydrolysis from rice straw (RS) pretreated by laccase with [AMIM]Cl or TritonX-100 and hydrolyzed with cellulase complex (50 FPU/g RS) and $\beta$-glucosidase (40 CBU/g RS) by four enzymatic saccharification strategies, $(\mathbf{a}-\mathbf{d})$, which were described in the Materials and Methods.

\subsection{SEM Images}

The morphological changes of untreated and pretreated rice straw were analyzed using SEM images (Figure 3). The untreated rice straw exhibits a smooth and rigid surface structure, whereas the surface of the pretreated rice straw with laccase only, laccase $+[\mathrm{AMIM}] \mathrm{Cl}$, and laccase + TritonX-100 is broken into fiber bundles or separated fibers, and cracks occur because of the removal of lignin and hemicellulose [24]. During further laccase $+[\mathrm{AMIM}] \mathrm{Cl}$ and laccase + TritonX-100 pretreatment, the surface morphology of the rice straw became looser with a wider separation of the fibers than that of rice straw pretreated with laccase only because most of the lignin and residual hemicellulose were removed during laccase and IL or surfactant pretreatment. The removal of both hemicellulose and lignins can improve enzymatic saccharification. The accessibility of enzymes to cellulose is a key factor influencing saccharification. The morphological investigation showed a significant increase in the surface area and porosity after pretreatment $[25,26]$. 

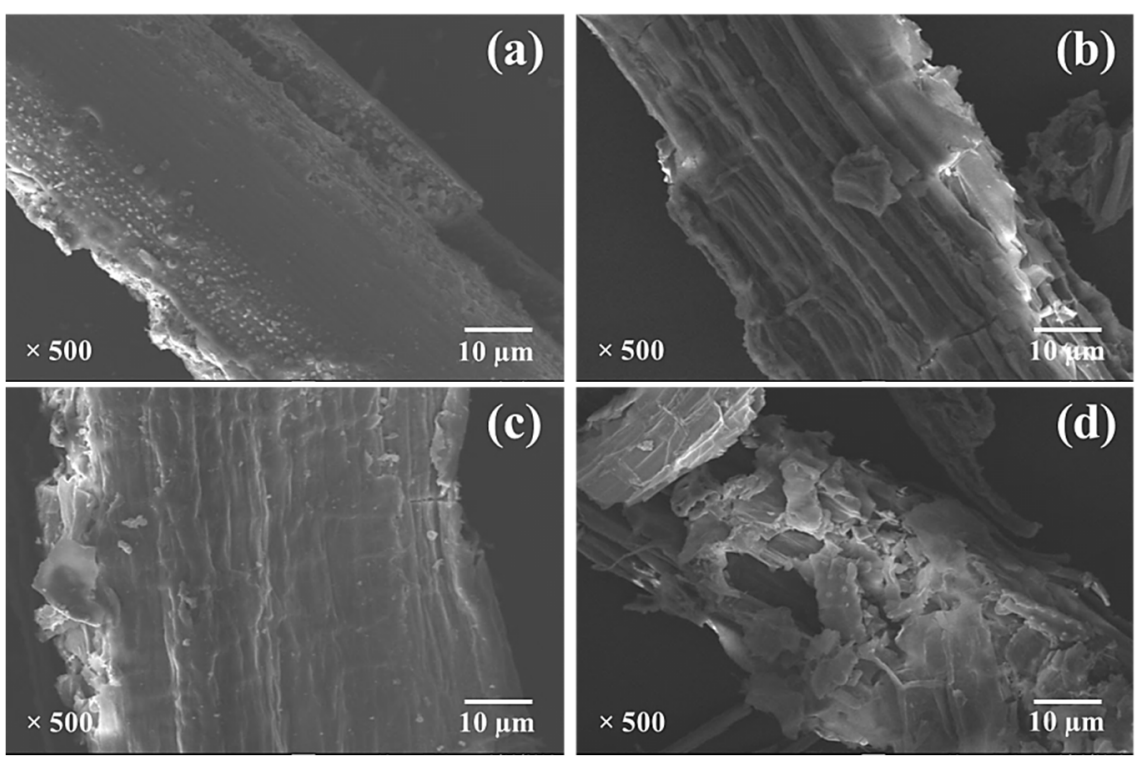

Figure 3. SEM images of untreated and pretreated rice straw. (a) Untreated rice straw, (b) laccase only, (c) laccase + [AMIM]Cl, (d) laccase + TritonX-100.

\subsection{Characterization of the Untreated and Pretreated Rice Straw}

FTIR and XRD spectra were obtained to monitor the changes of the chemical functional groups and the cellulose crystallization degree in rice straw (Figure $4 a, b$ ). The bands at 3405 and $2917 \mathrm{~cm}^{-1}$ representing the $\mathrm{O}-\mathrm{H}$ and $\mathrm{C}-\mathrm{H}$ stretching vibration confirm the appearance of the lignocellulosic matrix in both untreated and treated materials. The spectra of all pretreated samples show the strongest absorption band at $\sim 1035 \mathrm{~cm}^{-1}$. This band corresponds to the $\mathrm{C}-\mathrm{O}$ stretching vibration in both cellulose/hemicellulose and lignin $[27,28]$.
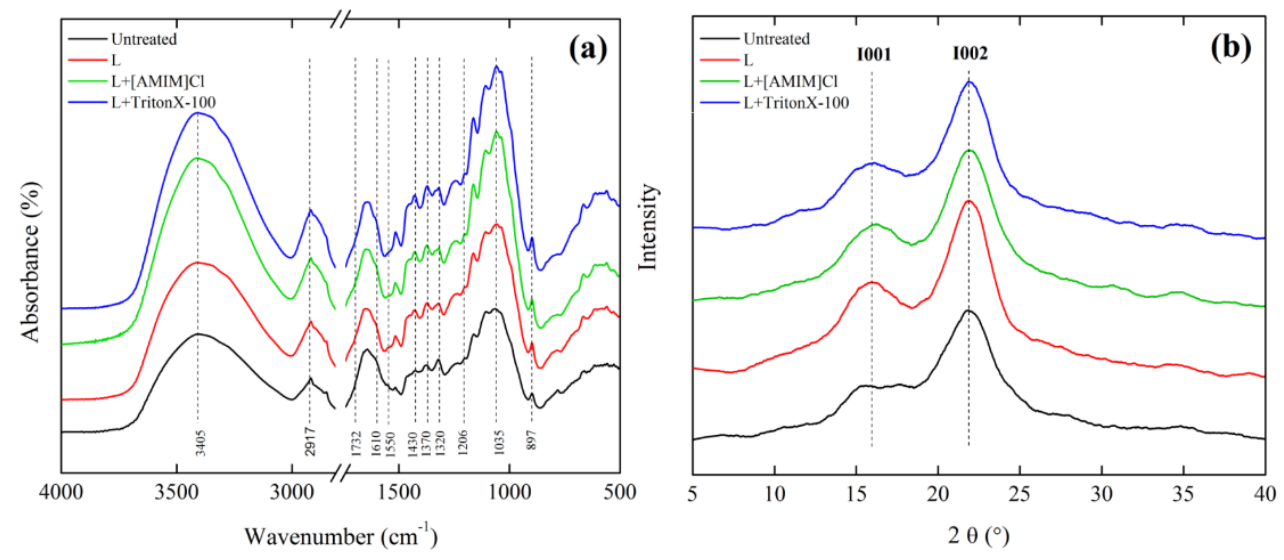

Figure 4. Spectrum analysis of rice straw under different pretreatment conditions. (a) FTIR spectra. (b) X-ray diffraction spectra.

The bands at 1370 and $1430 \mathrm{~cm}^{-1}$ also increased in all treated samples, which are associated with typical features of cellulose. The band at $1370 \mathrm{~cm}^{-1}$ corresponds to the bending vibration of $-\mathrm{CH}$ and stretching vibration of $\mathrm{C}-\mathrm{O}$. The band at $1512 \mathrm{~cm}^{-1}$ corresponds to the aromatic ring vibration. The band at $1423 \mathrm{~cm}^{-1}$ corresponding to the bending of $-\mathrm{CH}_{2}$ groups can be assigned to $-\mathrm{C}-6 \mathrm{CH} 2-$ of cellulose [29,30]. The band at $1732 \mathrm{~cm}^{-1}$, representing the $\mathrm{C}=\mathrm{O}$ stretching vibration of hemicellulose acetyl, reflects the hemicellulose content. After laccase-only, laccase $+[\mathrm{AMIM}] \mathrm{Cl}$, and laccase + TritonX-100 pretreatment, this band exhibited a declined absorbance, suggesting that parts of the hemicellulose degraded [31]. 
The characteristic lignin bands at $1206 \mathrm{~cm}^{-1}$ (syringyl ring and $\mathrm{C}-\mathrm{O}$ stretching vibration), $1320 \mathrm{~cm}^{-1}$ (C-O stretching vibration), $1548 \mathrm{~cm}^{-1}$ (aromatic skeleton $\mathrm{C}-\mathrm{C}$ stretching vibration in lignin), and $1610 \mathrm{~cm}^{-1}(\mathrm{C}=\mathrm{C}$ stretching vibration) were less intense in the spectra of laccase-only, laccase $+[\mathrm{AMIM}] \mathrm{Cl}$, and laccase + TritonX-100 treated samples in comparison with the untreated rice straw.

The lateral order index (LOI) and total crystallinity index (TCI) were determined as quantitative indices for the evaluation of the overall crystallinity of cellulose based on the FTIR spectra [32]. Higher values of LOI and TCI indicate that the material has a higher crystallinity and more ordered structure. In Table 2, the LOI of the rice straw pretreated with laccase only, laccase $+[\mathrm{AMIM}] \mathrm{Cl}$, and laccase + TritonX-100 is lower than the untreated rice straw. Therefore, FTIR confirms that laccase + TritonX-100 could mitigate the crystalline and ordered structure of cellulose in the rice straw more effectively than laccase $+[\mathrm{AMIM}] \mathrm{Cl}$ and laccase only.

Table 2. LOI, TCI, and CrI of untreated and pretreated rice straw.

\begin{tabular}{cccc}
\hline Pretreatments & LOI $\left(\mathbf{A}_{\mathbf{1 4 2 4}} / \mathbf{A}_{\mathbf{8 9 6}}\right)$ & TCI $\left(\mathbf{A}_{\mathbf{1 3 6 8}} / \mathbf{A}_{\mathbf{2 9 0 0}}\right)$ & CrI $\mathbf{~} \mathbf{\%})$ \\
\hline Untreated & 1.5955 & 1.2423 & 67.85 \\
L & 1.5774 & 1.2282 & 66.17 \\
L+[AMIM]Cl & 1.5746 & 1.1976 & 64.71 \\
L+TritonX-100 & 1.5689 & 1.1947 & 64.58 \\
\hline
\end{tabular}

The crystallinity of cellulose is considered to be a major factor influencing the enzymatic saccharification because amorphous cellulose can be hydrolyzed enzymatically much more rapidly than crystalline cellulose. The XRD profiles for untreated and pretreated rice straw exhibit typical diffraction peaks at approximately $2 \theta=16^{\circ}$ and $22.6^{\circ}$, which confirms that the crystal lattice type I of native cellulose was preserved, although it went through a series of treatments. The crystallinity index (CrI) value can be calculated based on Equation (2). The low CrI value reflects a high amount of amorphous cellulose in the regenerated cellulose [30]. All rice straw pretreated with laccase only $(66.17 \%)$, laccase + [AMIM]Cl $(64.71 \%)$, and laccase + TritonX-100 (64.58\%) has a lower CrI than untreated rice straw (Table 2). The results confirm that the rice straw regenerated from laccase + TritonX-100 pretreatment exhibits the highest surface area.

\subsection{AFM}

The AFM was used to examine samples at resolutions in three dimensions. The untreated and pretreated rice straw were analyzed using the software Nanoscope Analysis (Version 1.50). The square roughness $(\mathrm{Rq})$, average roughness $(\mathrm{Ra})$, and surface area (Sa) values were calculated by the software. The results reveal that the untreated rice straw appears to have a relatively well-oriented structure (Figure 5a). After the laccase, laccase $+[\mathrm{AMIM}] \mathrm{Cl}$, and laccase + TritonX-100 pretreatment (Figure $5 \mathrm{~b}-\mathrm{d}$ ), the surface structure of the rice straw is much rougher in comparison with the untreated rice straw. Moreover, the structure of the surface of the pretreated rice straw is uneven and nonuniformly covered with visible microfiber fragments, indicating that the fiber surface was modified after pretreatment. The surface area increased from 1,001,664 $\mathrm{nm}^{2}$ (untreated rice straw) to 1,069,663 $\mathrm{nm}^{2}, 1,064,632 \mathrm{~nm}^{2}$, and 1,081,602 $\mathrm{nm}^{2}$ after pretreatment with laccase only, laccase $+[\mathrm{AMIM}] \mathrm{Cl}$, and laccase + TritonX-100, respectively. The Rq and Ra significantly increased (Table 3). The [AMIM]Cl and TritonX-100-enhanced performance of the laccase pretreatment caused a dramatic roughness change. 

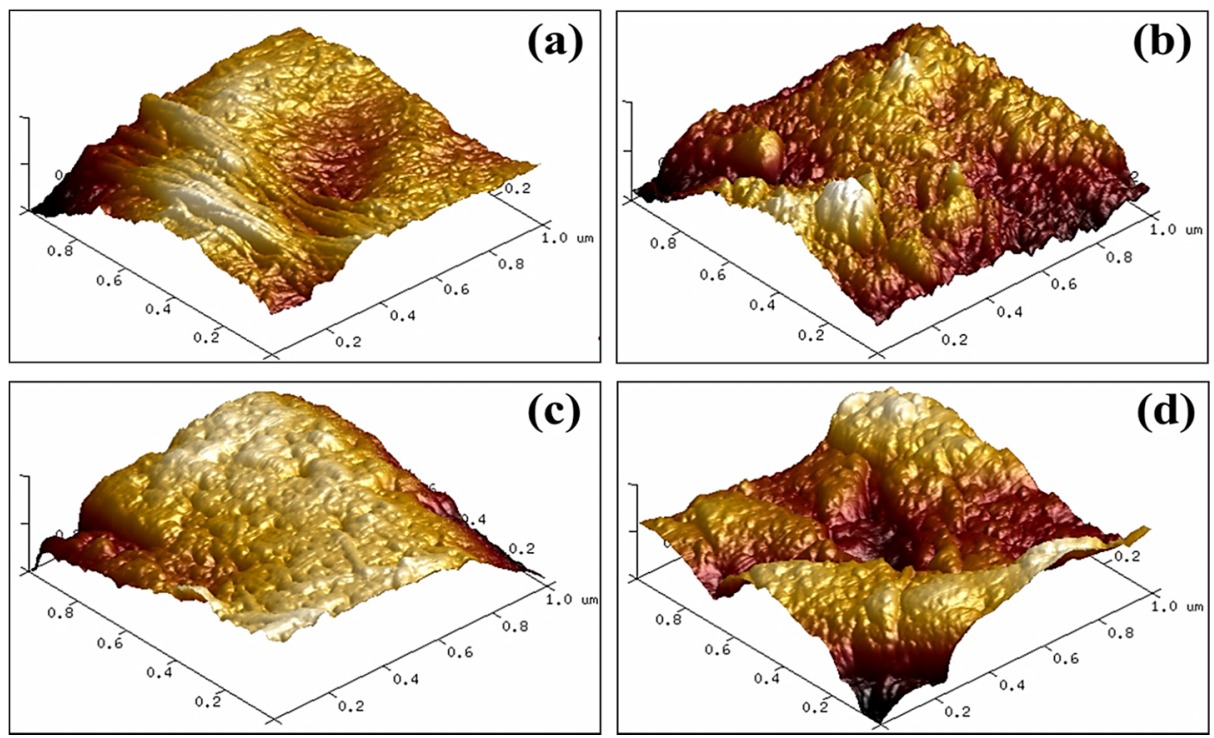

Figure 5. 3D AFM morphology images of rice straw. (a) Untreated, (b) laccase only, (c) laccase + [AMIM]Cl, (d) laccase + TritonX-100.

Table 3. AFM surface roughness factor of untreated and pretreated rice straw.

\begin{tabular}{|c|c|c|c|}
\hline Pretreatment & $\begin{array}{c}\text { Square Roughness } \\
\text { (Rq) }\end{array}$ & $\begin{array}{c}\text { Average Roughness } \\
\text { (Ra) }\end{array}$ & $\begin{array}{c}\text { Surface Area } \\
\left(\mathrm{Sa}, \mathrm{nm}^{2}\right)\end{array}$ \\
\hline Untreated & 4.89 & 3.99 & $1,001,664$ \\
\hline $\mathrm{L}$ & 12.30 & 9.59 & $1,069,663$ \\
\hline $\mathrm{L}+[\mathrm{AMIM}] \mathrm{Cl}^{\mathrm{a}}$ & 19.8 & 15.5 & $1,064,632$ \\
\hline$L+$ TritonX-100 $b$ & 21.4 & 17.7 & $1,081,602$ \\
\hline
\end{tabular}

a: $750 \mathrm{mg} / \mathrm{L} ;{ }^{\mathrm{b}}: 500 \mathrm{mg} / \mathrm{L}$.

\section{Materials and Methods}

\subsection{Materials}

Rice straw was obtained from the Jimei District, Xiamen City, Fujian Province, China. The rice straw was dried under room temperature, ground to powder, and passed through a 40-mesh screen. Laccase prepared from fungus T. versicolor was purchased from Sigma (St. Louis, MO, USA). Polyethylene Glycol Octylphenol Ether (TritonX-100) was purchased from Shanghai Aladdin Co. Ltd., Shanghai, China, and [AMIM]Cl was purchased from Shanghai Monils Chem. Eng. Sci. \& Tech. Co. Ltd., Shanghai, China. All experiments were performed in triplicate under the same conditions.

\subsection{Rice Straw Pretreatment}

Rice straw (0.5 g) was pretreated with laccase only (2 U/g substrate) or with laccase in the presence of [AMIM]Cl (100-1000 mg/L) or TritonX-100 (100-1000 mg/L) in $5 \mathrm{~mL}$ buffer with $0.1 \mathrm{M}$ citrate, $\mathrm{pH} 4.5$ (substrate concentration: 10\%). The pretreatment was carried out in $50 \mathrm{~mL}$ conical flasks incubated at $50{ }^{\circ} \mathrm{C}$ using a shaking incubator operating at $150 \mathrm{rpm}$ for $24 \mathrm{~h}$. The rice straw was washed with water until the $\mathrm{pH}$ was 7.0 and dried at $60{ }^{\circ} \mathrm{C}$ for $24 \mathrm{~h}$. Untreated rice straw was used as a control sample. The solid recovery and composition of the untreated and pretreated rice straw were also analyzed according to the method described in Jung et al. [33].

\subsection{Enzymatic Saccharification}

The enzymatic saccharification was performed in $25 \mathrm{~mL}$ flasks using $2.5 \%$ of rice straw in $0.1 \mathrm{M}$ sodium citrate buffer $(\mathrm{pH} 4.8)$ containing $0.02 \%$ of sodium azide to prevent bacterial growth. The rice straw was hydrolyzed by a commercial $\beta$-glucosidase (Novozyme NS221118) with 40 CBU/g rice straw and cellulase complex (Novozyme NS220086) with 
$50 \mathrm{FPU} / \mathrm{g}$ rice straw at $50{ }^{\circ} \mathrm{C}$ on a shaking incubator operating at $150 \mathrm{rpm}$ for $72 \mathrm{~h}$. The samples were then collected and centrifuged at 10,000 rpm for $10 \mathrm{~min}$. The total reducing sugar was analyzed using the dinitrosalicylic acid (DNS) method with glucose as the standard [30]. The absorption was measured at $575 \mathrm{~nm}$ using a UV-vis spectrophotometer (U-2900, HITACHI, Tokyo, Japan).

Four parallel experimental conditions were determined during the enzymatic saccharification step: (a) before enzymatic saccharification, the pretreated rice straw was filtrated and washed with distilled water until the $\mathrm{pH}$ of the washing water was 7.0; (b) the pretreated rice straw was not filtrated and washed before enzymatic saccharification; (c) the pretreated rice straw was boiled at $100{ }^{\circ} \mathrm{C}$ for $20 \mathrm{~min}$ to deactivate laccase, and enzymatic hydrolysis was carried out after it cooled; and (d) simultaneous laccase pretreatment and enzymatic saccharification were conducted in a flask. The cellulose conversion was determined as follows:

$$
\text { Cellulose conversion }(\%)=\frac{\text { Reducing sugar }(\mathrm{g} / \mathrm{L}) \times 0.9}{\text { Holocellulose in pretreated rice straw }} \times 100
$$

\subsection{SEM Analysis}

The morphologies of untreated and pretreated rice straw were determined by a scanning electron microscope (SEM; Zeiss Gemini 450, Oberkochen, Germany). After freeze-drying, the samples were mounted on the powder sample stubs by a carbon tape and coating by $30 \mathrm{~nm}$ thick conductive gold layer.

\subsection{FTIR Analysis}

The structural characteristics of untreated and pretreated rice straw were determined by an FTIR spectrometer (Nicolet 6700, Thermo Fisher Scientific, Waltham, MA, USA) at $4 \mathrm{~cm}^{-1}$ resolution from 400 to $4000 \mathrm{~cm}^{-1}$. Total crystallinity index $(\mathrm{TCI}=1378 / 2900)$ and lateral order index ( $\mathrm{LOI}=1437 / 899)$ were determined using the absorption ratios. [34].

\subsection{XRD Analysis}

$X$-ray diffraction of untreated and pretreated rice straw was obtained with an X-ray diffractometer (D/MAX-2400, Rigaku, Tokyo, Japan). The sample was scanned in the range of $5-40^{\circ}(2 \theta)$ with a step size of $0.02^{\circ}$ and step time of $1 \mathrm{~s}$ at $40 \mathrm{kV}, 20 \mathrm{~mA}$, and ambient temperature. The crystallinity index (CrI) of the samples was calculated with the following equation [35]:

$$
\mathrm{CrI}=\left(\mathrm{I}_{002}-\mathrm{I}_{\mathrm{am}}\right) / \mathrm{I}_{002} \times 100 \%
$$

where $\mathrm{I}_{002}$ is the maximum intensity of the crystalline portion, and $\mathrm{I}_{\mathrm{am}}$ is the intensity of the amorphous portion.

\subsection{AFM Analysis}

To observe the variation in the roughness of the untreated and treated rice straw samples, AFM (Bruker Dimension FastScan, Bruker Co. Ltd., Ettlingen, Germany) was used. The topography images were recorded with a scan rate of $2.00 \mathrm{~Hz}$ using the standard peak force mode. The images were processed with Nanoscope Analysis version 1.50 software. The surface roughness includes the root-mean-square roughness $(\mathrm{Rq})$ and average roughness $(\mathrm{Ra})$, which are defined as follows:

$$
\begin{gathered}
\mathrm{Rq}=\frac{1}{N} \sum_{i=1}^{N}\left|Z_{i}-\bar{Z}\right| \\
\mathrm{Ra}=\sqrt{\frac{\sum_{i=1}^{N}\left(Z_{i}-\bar{Z}\right)^{2}}{N}}
\end{gathered}
$$


where $Z_{i}$ is the height of the $i$ th point with respect to the lowest one in the image, and $N$ is the total number of points of the image.

\section{Conclusions}

In this study, IL and surfactant were used to enhance the performance of laccase with respect to pretreated rice straw. The highest cellulose conversion was $40.96 \%$ and $38.24 \%$ using a combined pretreatment with laccase + TritonX-100 (500 mg/L) and laccase $+[\mathrm{AMIM}] \mathrm{Cl}(750 \mathrm{mg} / \mathrm{L})$, respectively, after $72 \mathrm{~h}$ of enzymatic sacchrification when the substrate was washed with distilled water. After laccase + [AMIM]Cl and laccase + TritonX100 pretreatment, notable morphological changes were observed due to the increased specific surface area of rice straw. Moreover, the FTIR, XRD, and AFM data reveal the change of the chemical functional group, cellulose crystallinity, and roughness, which is consistent with the increase of the sugar yield during enzymatic saccharification. These results suggest that IL and surfactant can enhance the pretreatment performance of laccase and enzymatic saccharification. Although promising results have been obtained in the present work, the reaction conditions need further optimization, mainly by increasing the solid loading and decreasing the laccase doses, in order to reach industrial feasibility.

Author Contributions: Methodology and Data Curation, C.-H.L., Y.-C.L. and M.-H.L.; WritingOriginal Draft Preparation, K.-L.C.; Writing-Review and Editing, P.P., K.R. and C.-D.D.; Project Administration, K.-L.C. and G.C.C.Y. All authors have read and agreed to the published version of the manuscript.

Funding: This research was funded by the Ministry of Science and Technology of Taiwan (109-2221E-110-020-MY2, 109-2221-E-110-021, 110-2221-E-110-037).

Data Availability Statement: The datasets analyzed during the current study are available from the corresponding author on reasonable request.

Acknowledgments: This study was supported by the TEEP@Asia Plus 2020-2021, Taiwan.

Conflicts of Interest: The authors declare no conflict of interest.

\section{References}

1. Gerbens-Leenes, P.W. Green, Blue and Grey Bioenergy Water Footprints, a Comparison of Feedstocks for Bioenergy Supply in 2040. Environ. Process. 2018, 5, 167-180. [CrossRef]

2. Vasco-Correa, J.; Li, Y. Solid-state anaerobic digestion of fungal pretreated Miscanthus sinensis harvested in two different seasons. Bioresour. Technol. 2015, 185, 211-217. [CrossRef]

3. Zaky, A.S.; Carter, C.E.; Meng, F.; French, C.E. A Preliminary Life Cycle Analysis of Bioethanol Production Using Seawater in a Coastal Biorefinery Setting. Processes 2021, 9, 1399. [CrossRef]

4. Binod, P.; Sindhu, R.; Singhania, R.R.; Vikram, S.; Devi, L.; Nagalakshmi, S.; Kurien, N.; Sukumaran, R.K.; Pandey, A. Bio-ethanol production from rice straw: An overview. Bioresour. Technol. 2010, 101, 4767-4774. [CrossRef] [PubMed]

5. Singh, R.; Srivastava, M.; Shukla, A. Environmental sustainability of bioethanol production from rice straw in India: A review. Renew. Sustain. Energy Rev. 2016, 54, 202-216. [CrossRef]

6. Lavarda, G.; Morales-delaRosa, S.; Centomo, P.; Campos-Martin, J.M.; Zecca, M.; Fierro, J.L.G. Gel-Type and Macroporous Cross-Linked Copolymers Functionalized with Acid Groups for the Hydrolysis of Wheat Straw Pretreated with an Ionic Liq-uid. Catalysts 2019, 9, 675. [CrossRef]

7. Charisteidis, I.; Lazaridis, P.; Fotopoulos, A.; Pachatouridou, E.; Matsakas, L.; Rova, U.; Christakopoulos, P.; Triantafyllidis, K. Cat-alytic Fast Pyrolysis of Lignin Isolated by Hybrid Organosolv—Steam Explosion Pretreatment of Hardwood and Softwood Biomass for the Production of Phenolics and Aromatics. Catalysts 2019, 9, 935. [CrossRef]

8. Dedes, G.; Karnaouri, A.; Topakas, E. Novel Routes in Transformation of Lignocellulosic Biomass to Furan Platform Chemicals: From Pretreatment to Enzyme Catalysis. Catalysts 2020, 10, 743. [CrossRef]

9. Mutschlechner, M.; Illmer, P.; Wagner, A.O. Biological pre-treatment: Enhancing biogas production using the highly celluloly-tic fungus Trichoderma viride. Waste Manage 2015, 43, 98-107. [CrossRef] [PubMed]

10. Dionisi, D.; Anderson, J.A.; Aulenta, F.; McCue, A.; Paton, G. The potential of microbial processes for lignocellulosic biomass conversion to ethanol: A review. J. Chem. Technol. Biotechnol. 2015, 90, 366-383. [CrossRef]

11. Aracri, E.; Vidal, T. Enhancing the effectiveness of a laccase-TEMPO treatment has a biorefining effect on sisal cellulose fibres. Cellulose 2012, 19, 867-877. [CrossRef] 
12. Ibrahim, V.; Mendoza, L.; Mamo, G.; Hatti-Kaul, R. Blue laccase from Galerina sp.: Properties and potential for Kraft lignin demethylation. Process. Biochem. 2011, 46, 379-384. [CrossRef]

13. Mustafa, A.; Poulsen, T.G.; Xia, Y.; Sheng, K. Combinations of fungal and milling pretreatments for enhancing rice straw biogas production during solid-state anaerobic digestion. Bioresour. Technol. 2017, 224, 174-182. [CrossRef] [PubMed]

14. Qiu, W.; Chen, H. Enhanced the enzymatic hydrolysis efficiency of wheat straw after combined steam explosion and laccase pretreatment. Bioresour. Technol. 2012, 118, 8-12. [CrossRef]

15. Yu, H.; Du, W.; Zhang, J.; Ma, F.; Zhang, X.; Zhong, W. Fungal treatment of cornstalks enhances the delignification and xylan loss during mild alkaline pretreatment and enzymatic digestibility of glucan. Bioresour. Technol. 2010, 101, 6728-6734. [CrossRef]

16. Elgharbawy, A.; Alam, Z.; Moniruzzaman, M.; Goto, M. Ionic liquid pretreatment as emerging approaches for enhanced enzymatic hydrolysis of lignocellulosic biomass. Biochem. Eng. J. 2016, 109, 252-267. [CrossRef]

17. Chang, K.-L.; Chen, X.-M.; Han, Y.-J.; Wang, X.-Q.; Potprommanee, L.; Ning, X.-A.; Liu, J.-Y.; Sun, J.; Peng, Y.-P.; Sun, S.-Y.; et al. Synergistic effects of surfactant-assisted ionic liquid pretreatment rice straw. Bioresour. Technol. 2016, 214, 371-375. [CrossRef]

18. Zhang, W.; Liu, J.; Wang, Y.; Sun, J.; Huang, P.; Chang, K. Effect of ultrasound on ionic liquid-hydrochloric acid pretreatment with rice straw. Biomass Convers. Biorefinery 2021, 11, 1749-1757. [CrossRef]

19. Jeoh, T.; Ishizawa, C.I.; Davis, M.F.; Himmel, M.E.; Adney, W.S.; Johnson, D.K. Cellulase digestibility of pretreated biomass is limited by cellulose accessibility. Biotechnol. Bioeng. 2007, 98, 112-122. [CrossRef]

20. Chang, K.-L.; Han, Y.-J.; Wang, X.-Q.; Chen, X.-M.; Leu, S.-Y.; Liu, J.-Y.; Peng, Y.-P.; Liao, Y.-L.; Potprommanee, L. The effect of surfactant-assisted ultrasound-ionic liquid pretreatment on the structure and fermentable sugar production of a water hyacinth. Bioresour. Technol. 2017, 237, 27-30. [CrossRef]

21. Virak, S.; Chang, K.L.; Phitsuwanb, P.; Ratanakhanokchaib, K.; Dong, C.D. Effect of microwave-assisted ionic liquid/acidic ionic liquid pretreatment on the morphology, structure, and enhanced delignification of rice straw. Bioresour. Technol. 2019, 293, 121929.

22. Naushad, M.; Alothman, Z.; Khan, A.B.; Ali, M. Effect of ionic liquid on activity, stability, and structure of enzymes: A review. Int. J. Biol. Macromol. 2012, 51, 555-560. [CrossRef]

23. Moirangthem, K.; Zaky, A.S.; Tucker, G.A. Microwave subcritical water pre-treatment and enzymatic hydrolysis of geo-graphical identification (GI) tag Indian black rice (Chakhao Poireiton) straw for fermentable sugar production. Biofuels 2021. [CrossRef]

24. Zhao, X.; Wang, L.; Liu, D.-H. Peracetic acid pretreatment of sugarcane bagasse for enzymatic hydrolysis: A continued work. J. Chem. Technol. Biotechnol. 2008, 83, 950-956. [CrossRef]

25. Chang, K.L.; Chen, X.M.; Wang, X.Q.; Han, Y.J.; Potprommanee, L.; Liu, Y.J.; Liao, Y.L.; Ning, X.A.; Sun, Y.; Huang, Q. Im-pact of surfactant type for ionic liquid pretreatment on enhancing delignification of rice straw. Bioresour. Technol. 2016, 227, 388-392. [CrossRef] [PubMed]

26. Chang, K.-L.; Wang, X.-Q.; Han, Y.-J.; Deng, H.; Liu, J.-Y.; Lin, Y.-C. Enhanced Enzymatic Hydrolysis of Rice Straw Pretreated by Oxidants Assisted with Photocatalysis Technology. Materials 2018, 11, 802. [CrossRef] [PubMed]

27. Hurtubise, F.G.; Krässig, H. Classification of fine structural characteristics in cellulose by infrared spectroscopy. Anal. Chem. 1960, 32, 177-181. [CrossRef]

28. Naik, S.N.; Goud, V.V.; Rout, P.K.; Jacobson, K.; Dalai, A.K. Characterization of Canadian biomass for alternative renewable biofuel. Renew. Energy 2010, 35, 1624-1631. [CrossRef]

29. Lu, P.; Hsieh, Y.-L. Preparation and properties of cellulose nanocrystals: Rods, spheres, and network. Carbohydr. Polym. 2010, 82, 329-336. [CrossRef]

30. Jiang, F.; Hsieh, Y.-L. Chemically and mechanically isolated nanocellulose and their self-assembled structures. Carbohydr. Polym. 2013, 95, 32-40. [CrossRef]

31. Zhang, Z.; O'Hara, I.; Doherty, W. Pretreatment of sugarcane bagasse by acid-catalysed process in aqueous ionic liquid solutions. Bioresour. Technol. 2012, 120, 149-156. [CrossRef] [PubMed]

32. Zhao, H.; Jones, C.L.; Baker, G.; Xia, S.; Olubajo, O.; Person, V.N. Regenerating cellulose from ionic liquids for an accelerated enzymatic hydrolysis. J. Biotechnol. 2009, 139, 47-54. [CrossRef] [PubMed]

33. Jung, S.-J.; Kim, S.-H.; Chung, I.-M. Comparison of lignin, cellulose, and hemicellulose contents for biofuels utilization among 4 types of lignocellulosic crops. Biomass Bioenergy 2015, 83, 322-327. [CrossRef]

34. Miller, G.L. Use of Dinitrosalicylic Acid Reagent for Determination of Reducing Sugars. Anal. Chem. 1959, 31, 426-428. [CrossRef]

35. Martinez-Pavetti, M.; Medina, L.; Espinola, M.; Monteiro, M. Study on two eco-friendly surface treatments on Luffa cylindrical for development of reinforcement and processing materials. J. Mater. Res. Technol. 2021, 14, 2420-2427. [CrossRef] 